\title{
Supplement for Aromatic acids in a Eurasian ice core: a 3,000-year proxy record of biomass burning
}

Mackenzie M. Grieman*1, Murat Aydin ${ }^{1}$, Diedrich Fritzsche ${ }^{2}$, Joseph R. McConnell ${ }^{3}$, Thomas Opel $^{2,4}$, Michael Sigl ${ }^{5}$ and Eric S. Saltzman ${ }^{1}$

1 Department of Earth System Science, University of California, Irvine, Irvine, California, 92697-3100, USA

2 Alfred Wegener Institute Helmholtz Centre for Polar and Marine Research, Potsdam, Germany

3 Division of Hydrologic Sciences, Desert Research Institute, Reno, Nevada, USA

4 Permafrost Laboratory, Department of Geography, University of Sussex, Brighton, UK

5 Laboratory of Environmental Chemistry, Paul Scherrer Institut, Villigen, Switzerland
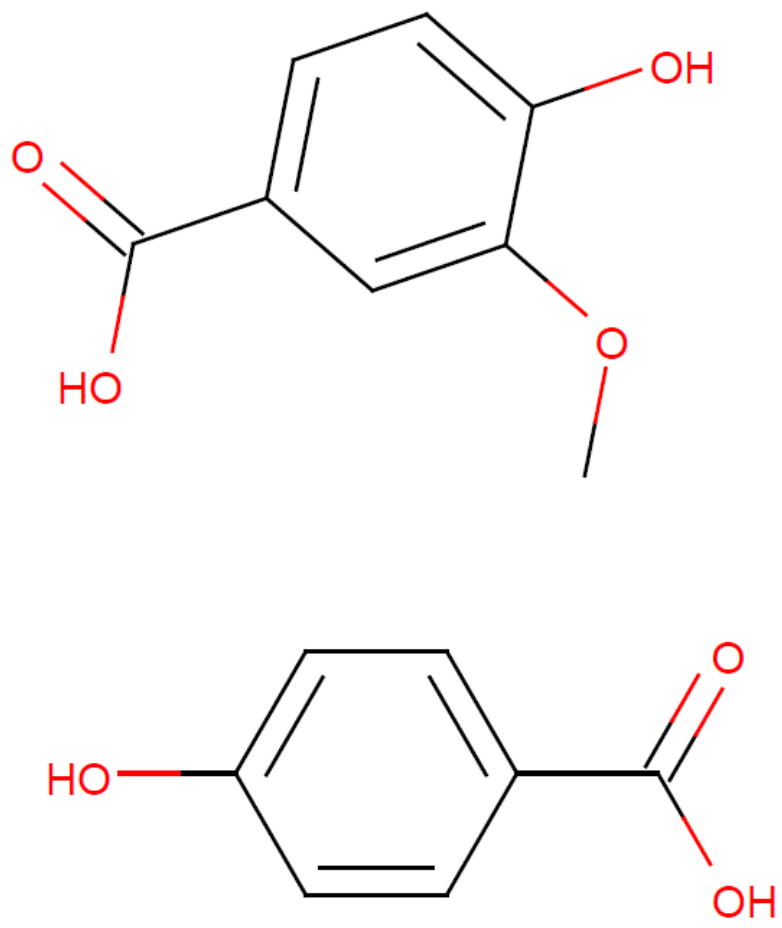

Figure S1: Molecular structures of vanillic acid $\left(\mathrm{C}_{8} \mathrm{H}_{8} \mathrm{O}_{4}\right.$; top) and para-hydroxybenzoic acid $\left(\mathrm{C}_{7} \mathrm{H}_{6} \mathrm{O}_{3}\right.$; bottom).

*correspondence to: mgrieman@uci.edu 


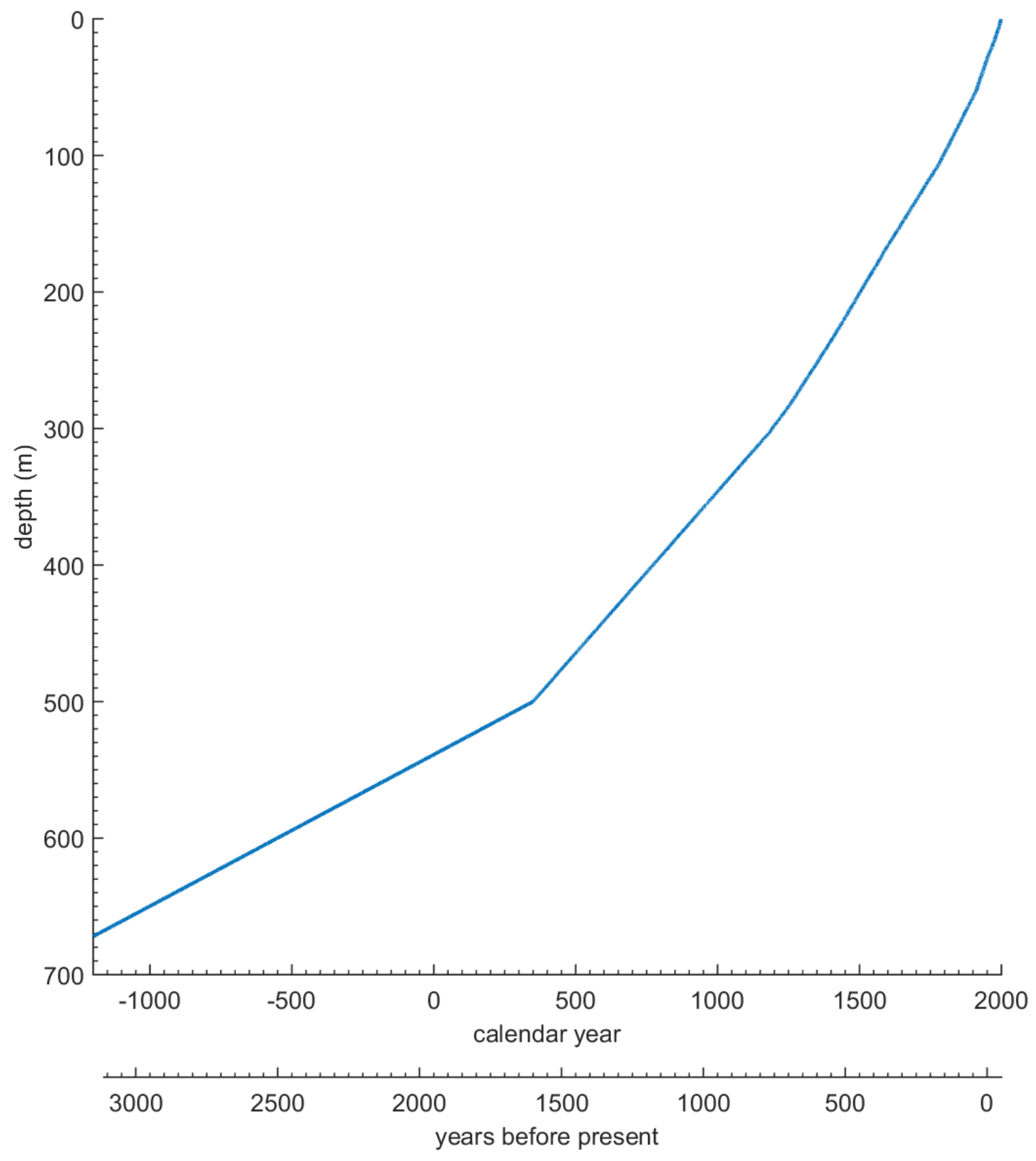

Figure S2: Akademii Nauk ice core depth-age scale. This age scale was determined using correlation between high resolution multi-element continuous flow analysis on this and other Arctic ice cores (Sigl et al., 2013). We note that this timescale yields a record that is longer than was predicted by an earlier published timescale based on volcanic sulphate signals and annual layer counting of stable water isotopes (Opel et al., 2013). 

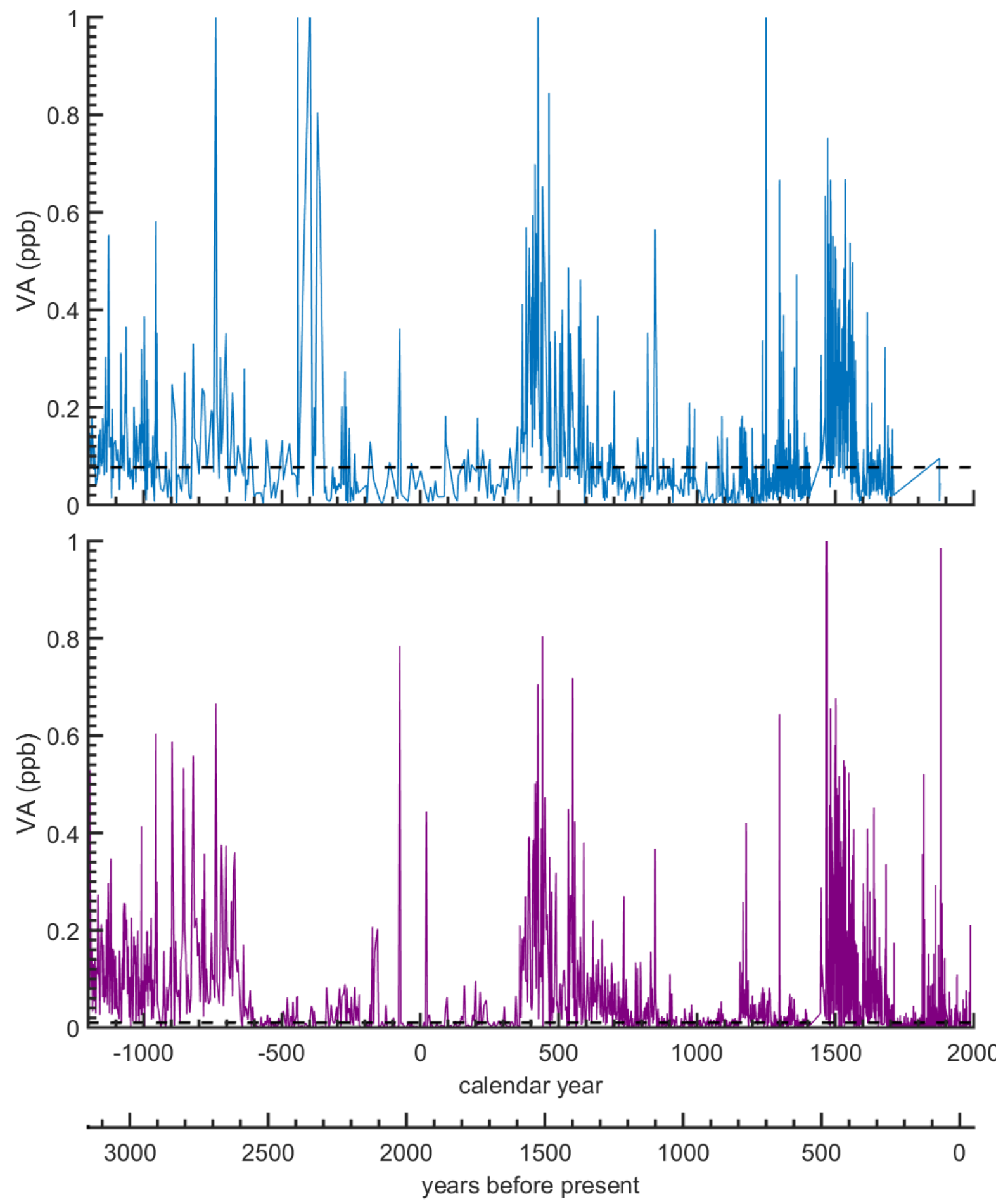

Figure S3: Akademii Nauk vanillic acid ice core measurements using two different analytical techniques. Top - High performance liquid chromatography with electrospray ionization and tandem mass spectrometry (HPLC-ESI/MS/MS); Bottom - Ion chromatography with electrospray ionization and tandem mass spectrometry (IC-ESI/MS/MS). Dotted horizontal lines are the limits of detection. Similar results were obtained by both techniques. IC-ESI/MS/MS has a significantly lower detection limit and improved quantitation over HPLC-ESI/MS/MS. 

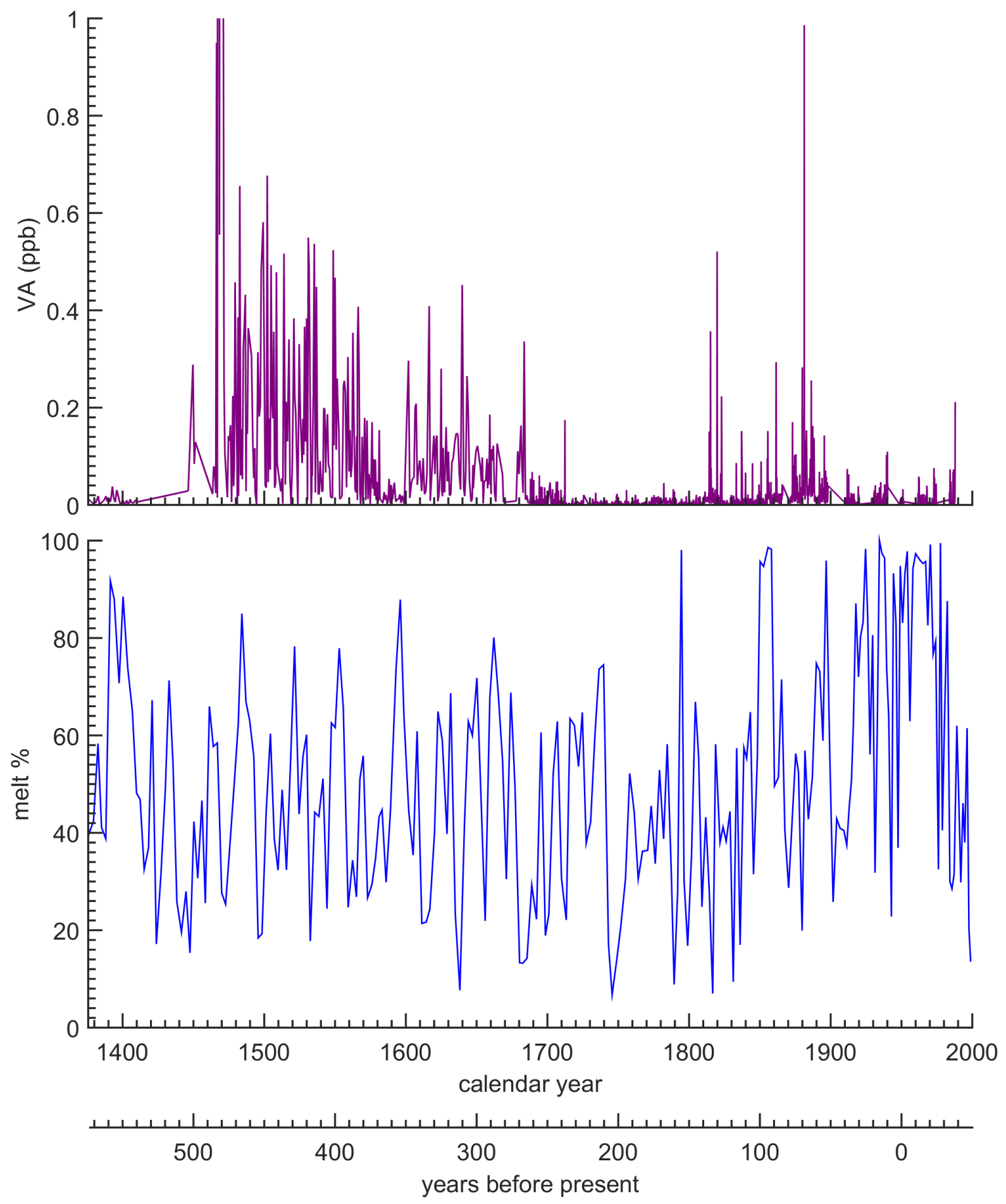

Figure S4: Akademii Nauk vanillic acid (top) and the distribution of melt layers in the ice core (bottom). 

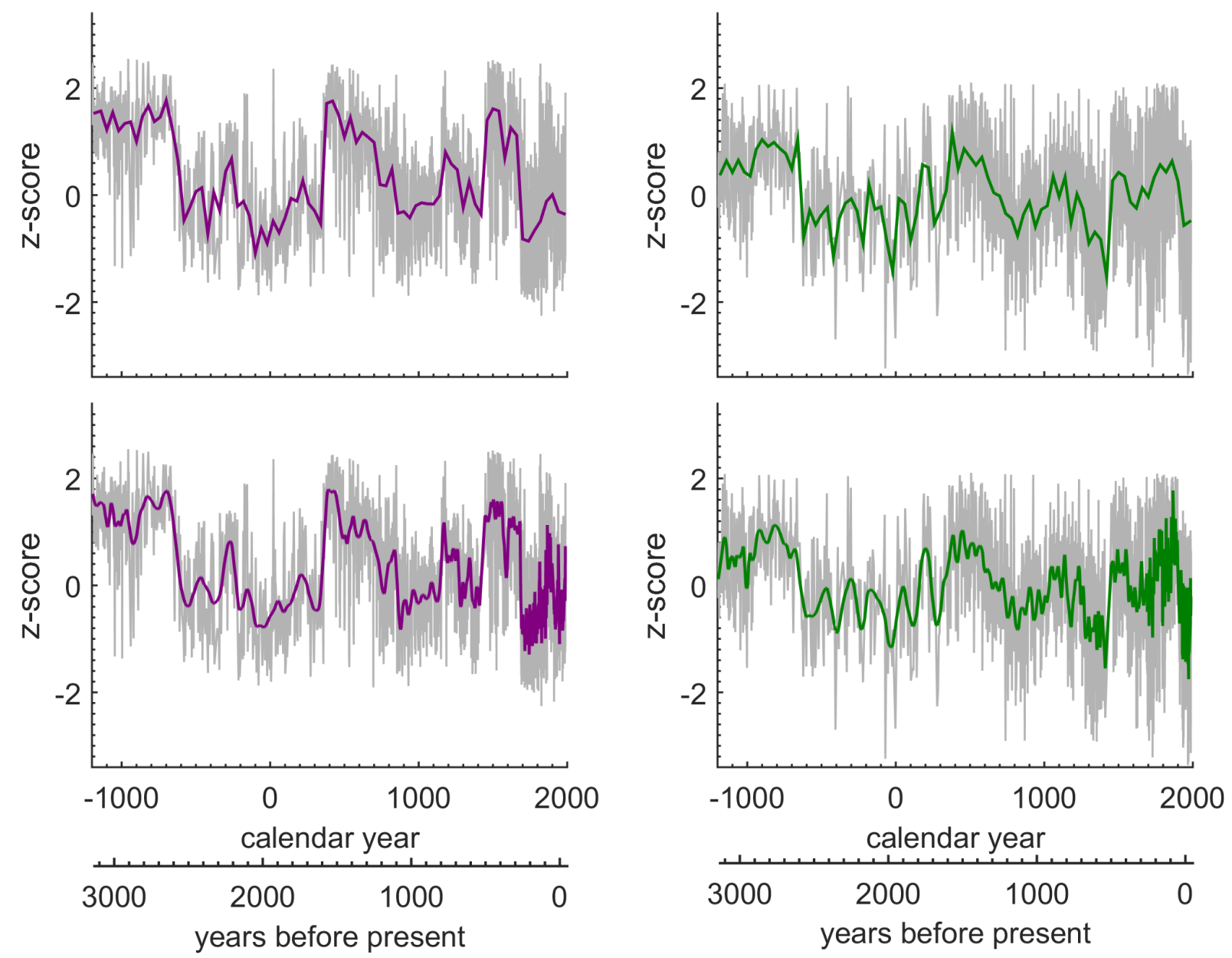

Figure S5: Akademii Nauk vanillic acid (left) and para-hydroxybenzoic acid (right) using 40-year bin averaging (top) and LOESS smoothing (span $=0.013$ ) (bottom). Outliers were omitted prior to analyses. Data were normalized using the log transformation, mini-max transformation, and the z-score (grey lines). 

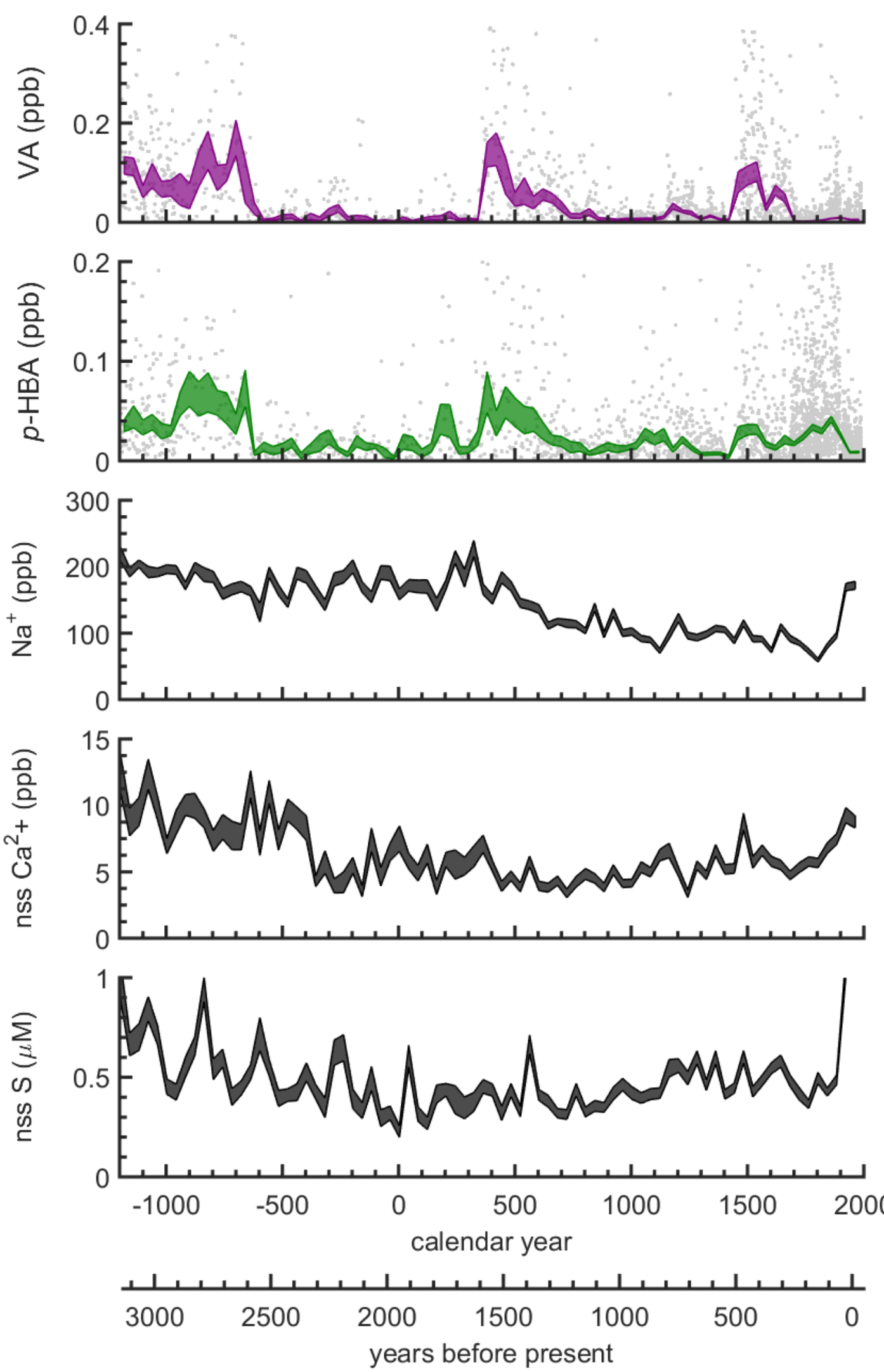

Figure S6: Akademii Nauk ice core chemistry over the past 3,000 years. Data are 40-year bin-averaged (fills are \pm 1 standard error of log transform) measurements. From top: 1) VA measurements, 2) p-HBA measurements, 3) sodium, 4) non-sea salt calcium, and 5) non-sea salt sulphur. 


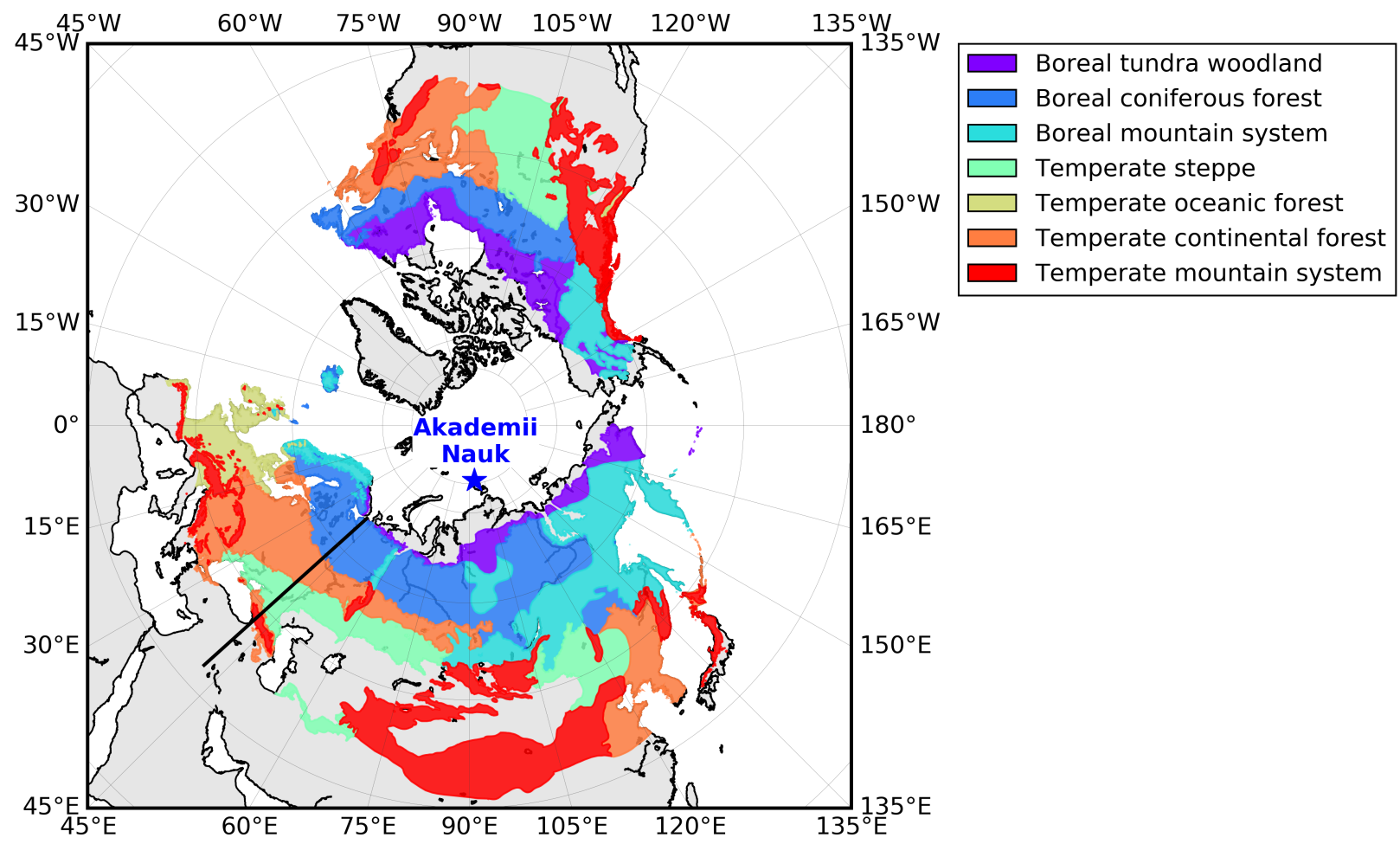

Figure S7: Map of ecofloristic zones defined by the Food and Agriculture Organization (Ruesch and Gibbs, 2008). The black line defines the boundary $\left(42^{\circ} \mathrm{E}\right)$ between Siberia and Europe used for HYSPLIT trajectory analysis. 


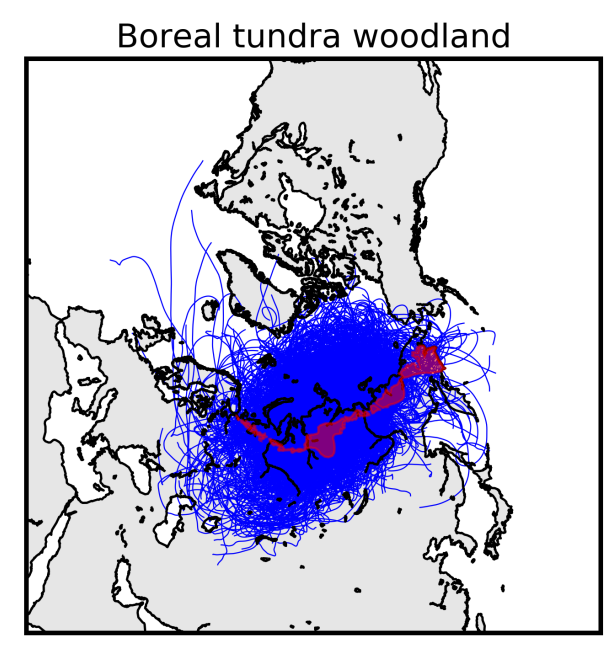

Boreal mountain system

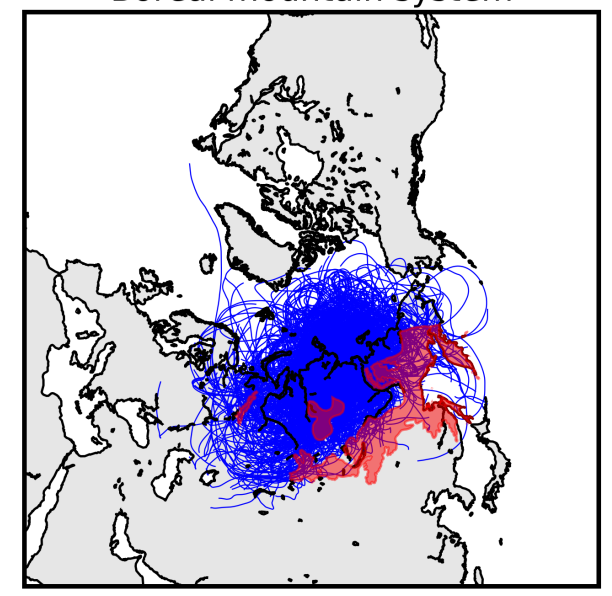

Temperate continental forest

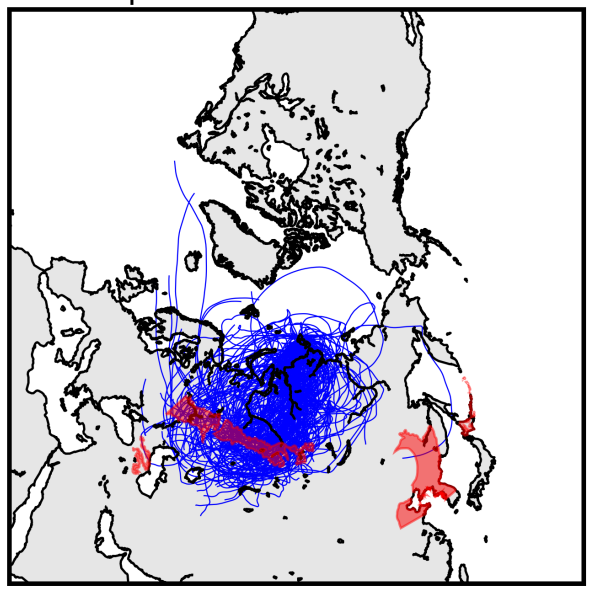

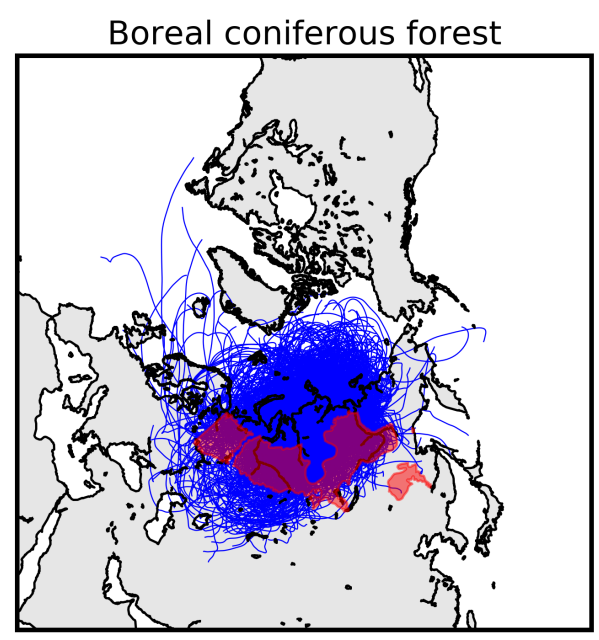

Temperate steppe

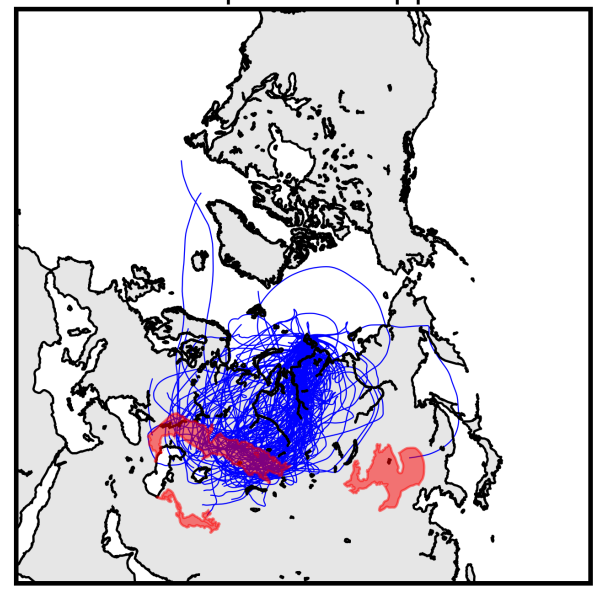

Temperate mountain system

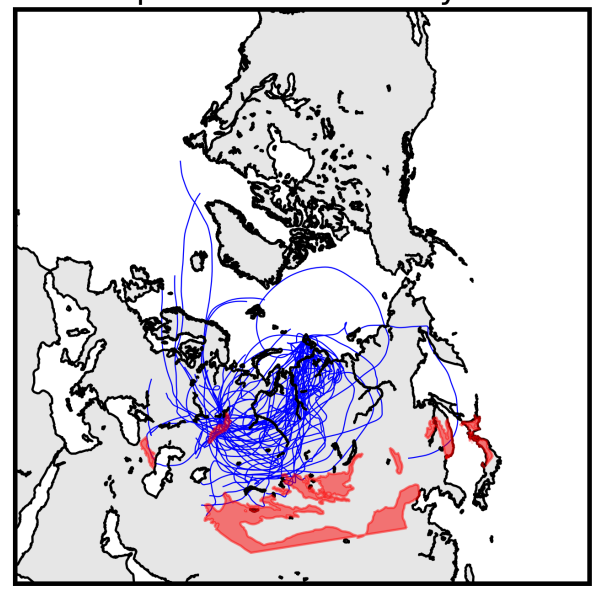

Figure S8: Maps of 10-day air mass back-trajectories using the HYSPLIT model from the Akademii Nauk ice core site. All back trajectories start at 12:00 AM and 12:00 PM from $100 \mathrm{~m}$ above ground level for the years 2006-2015 CE. Blue lines are trajectories from spring, summer, and fall (March 1-November 30) that transect or originate from each of the Siberian ecofloristic zones. Siberia is defined as landmass east of $42^{\circ} \mathrm{E}$. The ecofloristic zones (red) are defined by the Food and Agriculture Organization (Ruesch and Gibbs, 2008). Left panel from top: 1) Boreal tundra woodland, 2) Boreal mountain system, and 3) Temperate continental forest. Right panel from top: 1) Boreal coniferous forest, 2) Temperate steppe, and 3) Temperate mountain system. 


\section{References}

Opel, T., Fritzsche, D., and Meyer, H.: Eurasian Arctic climate over the past millennium as recorded in the Akademii Nauk ice core (Severnaya Zemlya), Clim. Past, 9, 2379-2389, doi:10.5194/cp-9-2379-2013, cP, 2013.

Ruesch, A. and Gibbs, H. K.: New IPCC Tier-1 global biomass carbon map for the year 2000, 2008.

Sigl, M., McConnell, J. R., Layman, L., Maselli, O., McGwire, K., Pasteris, D., Dahl-Jensen, D., Steffensen, J. P., Vinther, B., Edwards, R., Mulvaney, R., and Kipfstuhl, S.: A new bipolar ice core record of volcanism from WAIS Divide and NEEM and implications for climate forcing of the last 2000 years, Journal of Geophysical Research: Atmospheres, 118, 1151-1169, doi:10.1029/2012JD018603, 2013. 